\title{
Urban-rural Comparison of Children's Education Investment in Compulsory Education
}

\author{
Zhang Depeng ${ }^{1}$ Shi Zhenlei*2 \\ ${ }^{1}$ School of Economics and Management Beijing Jiaotong University Bei Jing, China \\ ${ }^{2}$ School of Economics and Management Beijing Jiaotong University Bei Jing, China
}

\begin{abstract}
Family education investment is an important mechanism that affects the stratification of urban and rural education in China. This article analyzes the urban-rural gap in China's family education investment and focuses on comparing the two levels of family education expenditure and education participation. The study found that the total expenditure for children 's education in urban households during compulsory education is higher than that in rural households, and the gap between the two in terms of extra-school tutoring expenditure is even greater. In terms of family education participation, the education participation behavior of urban families among children of compulsory education stage is more frequent, and the counseling time is longer than that of rural families. Rural families' care for their children's life and learning is significantly weaker than urban families. The comparative study of urban and rural family education investment in this article is helpful to understand the formation of urban and rural education inequality, and to grasp the specific differences between urban and rural family children's education investment in compulsory education stage.
\end{abstract}

\section{INTRODUCTION}

For more than 40 years of reform and opening up, China has attached great importance to the development of education and has made a leap in education. In 2011, China basically achieved the goal of "schooling" for school-aged children, and completed the comprehensive popularization of compulsory education. By 2018, the nine-year compulsory education consolidation rate had reached $94.20 \%$.

The gap in education opportunities between urban and rural areas in the compulsory education stage is narrowing. Since ancient times, the emphasis on children's education investment has always existed in Chinese families. The rapidly expanding scale of family education investment has greatly compensated for the lack of public education expenditures in $\mathrm{China}^{[1]}$, and the gap between urban and rural family education investment will definitely hinder society steady development. The difference between urban and rural family economic status, cultural capital, and social capital will further reflect the investment in family education ${ }^{[2]}$.

Broadly speaking, family education investment includes multiple dimensions, including not only monetary resources such as education expenditure, but also non-monetary resources such as time and spiritual input. The material security of the children's education, learning environment and information depends on the family's financial expenditure. Some studies (Zeng Manchao, 2010; Yuan Cheng, 2013; Qian Xiaoye et al., $2015)^{[3][4][5]}$ believe that there are significant differences between urban and rural households in children's education expenditure, and rural households' education expenditure is lower than that of urban households. In addition, there are obvious gaps in many items such as data fees and tutoring fees. This gap is particularly prominent in extracurricular tutoring expenditures; and households with non-local agricultural registration have to bear higher pressure on education investment. However, there are also studies (Gu Hongwei and Yang Qiuping, 2014) ${ }^{[6]}$ that household registration is not a significant factor affecting the difference in family education expenditures, especially after controlling the impact of household income.

The level of family education participation has a long-term impact on the children's academic performance. Investing more time and energy into the children's life and learning will reflect their learning interest and academic performance to a certain extent. The differences in culture and life between urban and rural areas and the difference in the education level of parents in urban and rural families have led to large differences in the way children are raised in urban and rural families (Zhang Wenxin, 1997) ${ }^{[7]}$. Compared with urban families, the parents of rural families are more concerned about the material needs of their children, but

a568624137@qq.com ${ }^{\text {b* }}$ zhlshi@bjtu.edu.cn 
their education methods are too simple, lack of emotional support and communication (Li Liju, Jia Yijiao, 2012) ${ }^{[8]}$.

Compared with the government actively formulating and adjusting policies to narrow the urban-rural differences in the allocation of educational resources, the family as the key joint affecting the development of children's education, the difference in education investment between urban and rural families has not received enough attention. In the past, different studies have focused on the economic aspects of urban and rural family education investment or a certain aspect of time and spiritual investment, and considering these two together helps to grasp the differences in urban and rural family education investment methods. This paper will use nationally representative data to make a comparative analysis of the investment status of urban and rural households in terms of family economic investment and educational participation (non-economic investment) in order to better understand the formation of urban-rural education gaps.

\section{RESEARCH DESIGN}

\section{A. Data Sources}

This article uses data from the 2016 "China Family Tracking Survey" (CFPS), which covers many research topics such as family economics, education, and health status. The analysis object selected in this paper is a sample of children in the CFPS children's library who are in the stage of compulsory education. After deleting the missing values of each variable, we obtained 3090 samples for analysis of family education monetary investment, and the analysis sample size of family education non-monetary input was 3140 .

\section{B. Variable}

This study includes two types of family education investment: "family education expenditure" and "education participation". The family's total expenditure on education and education tutoring expenditure for the whole year are selected to analyze the monetary expenditure level of family education. The former is measured by the question "Your child's education expenditure last year"; the latter is measured by "How much did your family pay for the child's tutoring in the past 12 months?"

The family's time and energy investment in children's education is used to reflect the degree of family participation in children's education, that is, family nonmonetary investment. This article selects a set of variables to reflect this situation, corresponding to the five questions in the questionnaire about participating in children's learning, "How long have you been tutoring children in the past week", "Abandon watching TV for children's learning", "I often talk with children about school "," Requires children to complete homework "," check children's homework ", and assign 1-5 to the last four items according to the actual situation of the answer. The distinction between urban and rural households is reflected in the selection of user registration in this article, and the status of the household registration at the time of the core independent variable questionnaire survey. The control variable is divided into four parts: child characteristic variable, parent characteristic variable, family characteristic variable and regional characteristic variable. Among them, the children's characteristic variables include gender, age, and the number of siblings; the parents' characteristic variables include the father's education level and the mother's education level; the family characteristic variables are expressed by the family's annual income (logarithm) and family education expectations. The regional characteristic variables are the dummy variables in the eastern, central and western regions, which are used to control the different influences of family education investment and parents 'outing due to regional differences.

\section{Result anAlysis}

\section{A. Descriptive Analysis}

The economic and non-economic levels of urban and rural households' investment in children's education are compared in the following three tables. As can be seen from Table 1, the average annual education expenditure of urban families on a single child is 3,546.90 yuan in compulsory education, while it is only 1877.27 yuan in rural areas, which is about $52.93 \%$ of urban families. The gap between urban and rural households in school expenditure is not large, but the gap between the two in terms of extracurricular tutoring expenditure is extremely obvious. Rural households are 158.18 yuan, only $13.62 \%$ of urban households. In terms of the structure of education expenditure, the expenditure on extracurricular tutoring for children in compulsory education in urban households is nearly one-third of the total education expenditure, while the proportion of rural households is only $8.43 \%$. This shows that during the compulsory education stage, urban and rural households are dominated by school education expenditures, but urban households pay more attention to their children's extracurricular tutoring expenditures than rural households. This aspect also accounts for $60.08 \%$ of the total urban-rural family education expenditure gap.

TABLE I. ANNUAL EDUCATION CURRENCY EXPENDITURE OF URBAN AND RURAL HOUSEHOLDS

\begin{tabular}{|l|l|l|l|l|}
\hline \multirow{2}{*}{} & \multicolumn{4}{|l|}{ Education expenditure } \\
\cline { 2 - 5 } & $\begin{array}{l}\text { Total } \\
\text { expenses }\end{array}$ & $\begin{array}{l}\text { School } \\
\text { education }\end{array}$ & $\begin{array}{l}\text { Shadow } \\
\text { education }\end{array}$ & $\begin{array}{l}\text { Proportion } \\
(\%)\end{array}$ \\
\hline Countryside & 1877.27 & 1735.19 & 158.18 & 8.43 \\
\hline City & 3546.90 & 2144.75 & 1161.26 & 32.74 \\
\hline Difference & 1669.63 & 409.56 & 1003.08 & 60.08 \\
\hline \multicolumn{5}{|c|}{ a. Shadow education expenditure as a proportion of total expenditure (\%) }
\end{tabular}

TABLE II. PARTICIPATION IN FAMILY EDUCATION

\begin{tabular}{|l|c|c|c|c|}
\hline & \multicolumn{4}{|l|}{ Educational participation } \\
\cline { 2 - 5 } & Rural & Urban & Total & Difference \\
\hline Question $1^{\mathrm{a}}$ & 55.13 & 64.31 & 56.87 & 9.18 \\
\hline Question 2 $^{\mathrm{b}}$ & 44.90 & 63.23 & 48.39 & 18.33 \\
\hline
\end{tabular}




\begin{tabular}{|l|c|c|c|c|}
\hline Question 3 $^{\text {c }}$ & 81.62 & 82.90 & 81.87 & 1.28 \\
\hline Question 4 & 50.57 & 59.29 & 52.23 & 8.72 \\
\hline Sample size & 3,140 & 737 & 3,877 & \\
\hline
\end{tabular}
$\begin{aligned} & \text { a. Give up entertainment for children's learning; b. I often talk about things in school with my } \\
& \text { children; }\end{aligned}$
c. Require children to complete homework; d. Check your child's homework

As can be seen from Table 2 above, rural families' care for their children's life and learning is significantly weaker than that of urban families. Urban parents pay more attention to maintaining communication with their children. In question 2, the urban-rural difference is 18 percentage points, followed by question 1 (the urbanrural percentage difference is 9.18).

In terms of requiring children to complete homework, urban and rural household data are more similar. Although most (more than $80 \%$ ) parents require their children to complete their homework, rural parents who can regularly check their children's homework are 8.72 percentage points lower than those in the city. This may be due to the differences in working hours and education level of parents of urban and rural families, but there may also be factors of differences in educational methods. The educational participation of rural families is more reflected in unilateral requirements rather than interactive participation.

TABLE III. WEEKLY HOMEWORK TIME FOR CHILDREN

\begin{tabular}{|l|l|l|l|l|}
\hline & \multicolumn{1}{|c|}{ Rural } & \multicolumn{1}{c|}{ Urban } & \multicolumn{1}{c|}{ Total } & \multicolumn{1}{c|}{ Difference } \\
\hline Tutoring time & 3.64 & 6.23 & 4.13 & 2.59 \\
\hline$\leq 1 \mathrm{~h} \mathrm{( \% )}$ & 50.99 & 34.46 & 47.85 & 16.53 \\
\hline$\geq 7 \mathrm{~h}(\%)$ & 24.44 & 43.01 & 28.01 & 18.57 \\
\hline
\end{tabular}

It can be seen from Table 3 that in terms of weekly homework for children, urban households are almost twice that of rural households. Overall, the city is 2.59 hours more per week for homework for children. However, more than half of the rural families have less than one hour of tutoring work per week, which is much higher than that of urban families, and rural households are 16.53 percentage points higher than urban families. The proportion of rural households who spent 7 hours on homework for children was less than one-third, while the proportion of urban households was $43.01 \%, 18.57$ percentage points higher than the former.

Taken together, urban families spend more time and energy in tutoring their children's homework every week, which may be related to the difference in cultural level between urban and rural areas. Urban families are more capable of providing homework guidance to their children.

\section{B. Empirical analysis}

This article divides the education investment of family children into two angles: money expenditure level and education participation. In the model analysis, the OLS model is used to estimate the level of children's education expenditure and the time of tutoring children. The specific model settings are as follows:

$$
\mathrm{Y}=\alpha+\beta * \mathrm{~W}_{\mathrm{i}}+\gamma * \mathrm{X}_{\mathrm{i}}+\varepsilon
$$

The dependent variable $Y$ in (1) is the annual family education expenditure of the child, including the total education expenditure and extracurricular expenditure involved in Table 5, and also includes the "time of tutoring children in a week" that measures family education participation in Table 6 . The variable $\mathrm{W}_{\mathrm{i}}$ represents the status of the household registration. $X_{i}$ sets a series of control variables for us, and $\varepsilon$ is a random disturbance term.

For family education participation, the sequential logit regression model is used to estimate the urban-rural gap in family education participation. The specific setting model is as follows:

$$
\operatorname{Logit}\left(P_{\mathrm{j}}\right)=\ln \left[\mathrm{P}(\mathrm{y} \leqslant \mathrm{j}) / \mathrm{P}(\mathrm{y} \leqslant \mathrm{j}+1]-\alpha_{\mathrm{j}}+\beta^{*} \mathrm{X}\right.
$$

In equation (2), $\mathrm{P}$ is the probability of a certain level of family education participation, $\mathrm{j}=1,2,3,4,5$; the dependent variable $\mathrm{Y}$ of the equation is a series of variables that measure family education participation (except for tutoring children within one week Time), $\mathrm{X}$ sets a series of independent variables for us, $\alpha_{j}$ is the intercept of the model.

In the regression results of total family education expenditure and extracurricular tutoring expenditure, the household registration variable is significant at the level of $5 \%$ and $1 \%$, respectively. In terms of annual family education expenditures on children, both in total and outof-school expenditures, urban households are significantly higher than rural households.

TABLE IV. DIFFERENCES IN EDUCATION EXPENDITURE BETWEEN

\begin{tabular}{|c|c|c|}
\hline & (1) & (2) \\
\hline variable & Total & Shadow education \\
\hline \multirow{2}{*}{ Hukou } & $0.229 * *$ & $3.199 * * *$ \\
\hline & $(0.0956)$ & $(0.740)$ \\
\hline \multirow{2}{*}{ Gender } & -0.0596 & $-0.900^{*}$ \\
\hline & $(0.0684)$ & $(0.527)$ \\
\hline \multirow{2}{*}{ Age } & $0.161 * * *$ & $0.384 * * *$ \\
\hline & $(0.0138)$ & $(0.104)$ \\
\hline \multirow{2}{*}{ Number of siblings } & $-0.133 * * *$ & $-0.963 * *$ \\
\hline & $(0.0382)$ & $(0.374)$ \\
\hline \multirow{2}{*}{ Eduf } & $0.0211 * *$ & 0.0153 \\
\hline & $(0.0103)$ & $(0.0839)$ \\
\hline \multirow{2}{*}{ Edum } & $0.0329 * * *$ & $0.375 * * *$ \\
\hline & $(0.00993)$ & $(0.0800)$ \\
\hline \multirow{2}{*}{ income } & $0.296^{* * *}$ & $0.743 * *$ \\
\hline & $(0.0409)$ & $(0.312)$ \\
\hline \multirow{2}{*}{ Educational expectations } & $0.0287 * *$ & $0.222 * *$ \\
\hline & $(0.0121)$ & $(0.0966)$ \\
\hline \multicolumn{3}{|l|}{ East $=0$} \\
\hline Central & $0.247 * * *$ & 0.878 \\
\hline
\end{tabular}
URBAN AND RURAL FAMILIES 


\begin{tabular}{|c|l|l|}
\hline & $(0.0807)$ & $(0.616)$ \\
\hline \multirow{2}{*}{ West } & $-0.718^{* * *}$ & $-2.980^{* * *}$ \\
\cline { 2 - 3 } & $(0.0884)$ & $(0.710)$ \\
\hline \multirow{3}{*}{ Constant } & $1.242^{* *}$ & $-25.40^{* * *}$ \\
\cline { 2 - 3 } & $(0.520)$ & $(3.929)$ \\
\hline Observations & 3,090 & 3,090 \\
\hline
\end{tabular}

Judging from the personal characteristics of the children, the impact of gender on the total expenditure on family education is not significant, but in extracurricular expenditure, the family's expenditure on boys is significantly lower than that on girls. The reason for this may be that in the compulsory education stage, girls study harder than boys and prefer to take the initiative to participate in off-campus training. Based on this situation, parents tend to read girls to invest more outside the school.

From the perspective of family characteristics, the number of children in the family has a significant negative effect on the children's total education expenditure and extracurricular expenditure. As the mother's education level improves, the child's total education expenditure and out-of-school curriculum costs have significantly increased, while the father's education level has only a significant positive effect on the child's total family expenditure on education, and has no significant impact on the child's off-campus investment .

The reason for this may be that mothers in the family pay more attention to their children's activities and learning outside the school, and play the role of decisionmaker in this process.

TABLE V.DIFFERENCES IN HOUSEHOLD REGISTRATION AND FAMILY EDUCATION PARTICIPATION

\begin{tabular}{|c|c|c|c|c|c|}
\hline & (1) & (2) & (3) & (4) & (5) \\
\hline variable & Question 1 & Question 2 & Question 3 & Question 4 & $\begin{array}{c}\text { Question5 } \\
\text { a }\end{array}$ \\
\hline \multirow{2}{*}{ Hukou } & $0.339^{* * *}$ & $0.324 * * *$ & 0.0777 & 0.0503 & $1.408^{* * *}$ \\
\hline & $(0.0967)$ & $(0.0911)$ & $(0.0977)$ & $(0.0924)$ & $(0.334)$ \\
\hline \multirow{2}{*}{ Gender } & -0.0811 & 0.0623 & $0.116^{*}$ & $0.223^{* * *}$ & 0.366 \\
\hline & $(0.0626)$ & $(0.0611)$ & $(0.0639)$ & $(0.0609)$ & $(0.243)$ \\
\hline \multirow{2}{*}{ Age } & $-0.0495 * * *$ & -0.0157 & $-0.0810 * * *$ & $-0.222 * * *$ & $-0.546^{* * *}$ \\
\hline & $(0.0131)$ & $(0.0124)$ & $(0.0129)$ & $(0.0130)$ & $(0.0497)$ \\
\hline \multirow{2}{*}{$\mathrm{N}^{\mathrm{b}}$} & $-0.0731^{*}$ & $-0.116 * * *$ & $-0.121 * * *$ & $-0.165 * * *$ & $-0.725^{* * *}$ \\
\hline & $(0.0381)$ & $(0.0397)$ & $(0.0395)$ & $(0.0393)$ & $(0.135)$ \\
\hline \multirow{2}{*}{ Eduf } & 0.00830 & $0.0373^{* * *}$ & 0.000279 & $0.0235^{* *}$ & -0.0394 \\
\hline & $(0.00948)$ & $(0.00945)$ & $(0.00977)$ & $(0.00934)$ & $(0.0380)$ \\
\hline \multirow{2}{*}{ Edum } & $0.0176^{* *}$ & $0.0606^{* * *}$ & $0.0170^{*}$ & $0.0560 * * *$ & $0.127^{* * *}$ \\
\hline & $(0.00879)$ & $(0.00900)$ & $(0.00922)$ & $(0.00904)$ & $(0.0345)$ \\
\hline \multirow{2}{*}{ Income } & -0.0646 & -0.0381 & 0.000105 & 0.0425 & $0.394 * * *$ \\
\hline & $(0.0404)$ & $(0.0371)$ & $(0.0357)$ & $(0.0358)$ & $(0.122)$ \\
\hline
\end{tabular}

\begin{tabular}{|c|l|l|l|l|l|}
\hline \multirow{2}{*}{ Exp } & $0.0446^{* * *}$ & $0.0511^{* * *}$ & 0.0115 & 0.0163 & $0.104^{* *}$ \\
\cline { 2 - 6 } & $(0.0122)$ & $(0.0121)$ & $(0.0127)$ & $(0.0126)$ & $(0.0434)$ \\
\hline \multirow{5}{|c|}{ East=0 } & 0.0441 & $-0.237^{* * *}$ & 0.0367 & -0.119 & $-1.055^{* * *}$ \\
\hline \multirow{3}{*}{ Central } & $(0.0773)$ & $(0.0738)$ & $(0.0798)$ & $(0.0728)$ & $(0.269)$ \\
\hline \multirow{3}{*}{ West } & -0.0197 & 0.0132 & 0.0913 & $0.434^{* * *}$ & $1.003^{* * *}$ \\
\cline { 2 - 6 } & $(0.0815)$ & $(0.0790)$ & $(0.0813)$ & $(0.0804)$ & $(0.319)$ \\
\hline \multirow{2}{*}{ Constant } & 3,140 & 3,140 & 3,140 & 3,140 & 3,140 \\
\hline
\end{tabular}

a. Weekly homework time for children; b. Number of siblings

Table 5 shows the regression results of household registration differences on the family's non-monetary investment in children's education. In general, urban families are more involved in the education of their children and invest more in their non-economics. Urban families' counseling time for children in a week is about 1.4 hours higher than that of rural families, and this time decreases significantly with the increase of children's age. The reason for this phenomenon may be that parents in urban families are more educated and more able to counsel their children. With the increase of children's age, the difficulty of the knowledge they learn also increases, which will restrict the time of family counseling.

At the same time, in the above table, we see that the age of the children is significantly positively correlated with out-of-school counseling expenditures, and the two may have a complementary effect. The father's education period is not significantly related to the family counseling time, but the mother is significantly positively related, which may be related to the "father role lack" phenomenon in the children's family education.

Among other educational participation behaviors, the household registration variable has the largest odds ratio for giving up watching TV for children's learning, which is about 1.40 , and it is significantly positively correlated at $1 \%$.In both question 2 and question 3, urban households perform better than rural households. Despite questions 4 and question 5, urban households 'participation in these two education activities is not significantly different from that of rural households. However, there are obvious gender differences between the two items, and the performance of the two educational participation behaviors for boys is significantly higher than that for girls.

In general, the economic and non-economic investment of urban families in child education is significantly higher than that of rural families. For children at the stage of compulsory education, urban families pay more attention to extracurricular tutoring. Rural families mainly pay for school education, and the expenditure on extracurricular tutoring is low. In terms of non-economic investment, urban families have more time for family counseling and more frequent communication and interaction with their children, but there is no significant difference in the level of participation in children's homework. 


\section{CONCLUSION AND SUGGESTION}

\section{A. Conclusion}

This article uses CFPS 2016 data to compare and analyze China's compulsory education stage urban and rural education investment status in two dimensions of monetary investment and non-monetary investment. The main conclusions are as follows:

a) The expenditure for children's education in urban households is significantly higher than that in rural households. With the rise of shadow education and the sharp increase in the demand for personalized and diversified education for family children, the gap between the two in terms of out-of-school tutoring expenditure is even greater. Shadow education is essentially a manifestation of the family's pursuit of better education, which will exacerbate the urban-rural inequality of family education and weaken the social mobility function of education.

b) In terms of non-economic investment, the participation of urban families in children in compulsory education is more frequent, and the counseling time is longer than that of rural families. Although there is no obvious difference in children's homework requirements and inspections, the time for urban families to tutor children is significantly higher than that for rural families. Generally speaking, urban families are more prominent in the communication and interaction of children's education.

\section{B. Suggestion}

The comparative study of urban and rural family education investment in this paper is helpful to understand the formation of urban and rural education inequality, grasp the specific differences of urban and rural family education investment in the current compulsory education stage, and make targeted suggestions.

a) Reasonable guidance should be provided for tutoring outside the school. The urban-rural gap in shadow education has widened the gap that originally existed between urban and rural education. Blind investment in children's shadow education will not only increase the financial burden of the family, but will also increase the burden of schoolwork for children. This behavior will also increase the educational risk of children from economically disadvantaged rural families.

In the final analysis, the existence of shadow education is due to the diversified needs of families for children's education. Schools should adopt a more flexible education model to meet the diverse needs of family education ${ }^{[9]}$ and improve the service level of mainstream education models. The government should also strengthen the management and supervision of the after-school tutoring market and standardize the family education investment behavior on the basis of standardizing the off-campus tutoring market.

b) Improve the parental participation of children's education. Parents in urban and rural families generally attach importance to family education, but they are stretched when transforming the concept of attention into a scientific method of education, which is particularly prominent in rural families. The government should focus on helping parents of rural families need to raise the awareness of family education participation, improve the level of participation, and pay attention to developing skills that promote benign intergenerational communication.

We should note that this "low participation" of rural households may not only be a lack of consciousness, but also largely due to lack of own abilities and knowledge. In the past, government policies mainly focused on the institutionalization of education. In the future, in addition to financial subsidies, in the future, the country should focus on promoting cooperation between families, communities, and schools, and raising the level of scientific family education for parents.

c) Raise the income level of rural families. Further narrowing the urban-rural income gap and reducing the dilemma of economically weak investment in family education. Take effective measures to alleviate the educational burden of poor families and guarantee the education expenditure of rural families. The intensity of public investment should be further expanded, the supplementary role of family education investment should be strengthened, and the education subsidy policy for poor families should be improved.

\section{ACKNOWLEDGMENT}

I am very grateful for the care and careful guidance given by my teacher, and put forward many valuable suggestions for improvement. I also want to thank my friends, for their patience in listening and helping, and for their care and care for me in life and study.

\section{REFERENCES}

[1] Cai Wenbo, Huang Jinsheng. Urban-rural Differences and Spatial Evolution of Family Education Investment in China [J] .Economic Review of Education, 2019,4 (06): 39-55.

[2] Liu Baozhong. "Gap" and "Chain of Despise": Class Differences in Family Education Investment: An Empirical Analysis Based on Beijing, Shanghai, Guangzhou and Megacities [J]. Journal of Beijing University of Technology (Social Science Edition), 2018, $18(02): 8-16$.

[3] Zeng Manchao. Ding Xiaohao. Shen Hua. Analysis on the Differences between Urban and Rural Extracurricular Tutorials for Junior Middle School Students: Based on Surveys of Extracurricular Tutorials for Junior Middle School Students in Gansu, Hunan and Jiangsu $[\mathbf{J}]$. Education and Economy, 2010 (2): 7-11.

[4] Yuan Cheng, Zhang Lei, Zeng Ying, 2013: "Effects of Local Education Investment on Educational Behavior of Urban Families: An Estimation of Dynamic Repetitive Cross-Section Data of Urban Families in China", "Economic Update" Issue 3.

[5] Qian Xiaozhang, Chi Wei, and Shi Yao, 2015: "Composition and Inequality of Educational Expenditure in Urban Families at the Compulsory Education Stage: Empirical Evidence from 2007 and 2011", Education and Economy, Issue 6.

[6] Gu Hongwei. The Impact of Income and Number of Children on Educational Behavior of Urban Families: An Empirical Study Based on Dalian [J]. Macroeconomic Research,2014 (5): 127 134.

[7] Zhang Wenxin. Comparative Study on Educational Methods of Parents in Urban and Rural Adolescents $[\mathrm{J}]$. Psychological Development and Education, 1997, 13 (3): 46-51

[8] Li Liju, Jia Yijiao. Comparison of Parental Rearing Patterns between Urban and Rural Elementary School Students [J]. Social Psychological Science, 2012 (12): 107-111. 
[9] Ding Xiaohao, Weng Qiuyi. Power Capital and Family Education Expenditure Model [J]. Peking University Education Review, 2015, 13 (3):130-142. 